\title{
High-velocity stars between the Magellanic Clouds
}

\author{
N. Meyssonnier \\ Observatoire de Marseille, 2 place Le Verrier, F-13248 Marseille Cedex 04, France
}

Received March 18; accepted November 5, 1998

\begin{abstract}
We report the positions of 12 new stars with high radial velocities $\left(>100 \mathrm{~km} \mathrm{~s}^{-1}\right.$ ) between the two Magellanic Clouds. These stars have been found using the Fehrenbach objective prism.
\end{abstract}

Key words: techniques: radial velocities — Magellanic Clouds

\section{Introduction}

Two papers on the search for stars with high radial velocities between the Magellanic Clouds have been published by Carozzi (1971) and Carozzi (1974). We report here the detection of a few new stars with high radial velocities on plates obtained by M. Duflot, A. Duflot, G. Amieux and J.C. Duflot with the $40-\mathrm{cm}$ diameter Fehrenbach objective prism installed at the European Southern Observatory at La Silla (Chile).

\section{Measurements and results}

The radial velocity measurements have been made on the sharpest spectral lines of the direct and inverted spectra obtained by turning the objective prism by $180^{\circ}$ around the axis of the telescope. They used the two-axes measuring machine of the Marseilles Observatory which is accurate to $1 \mu \mathrm{m}$ on each axis. I thank L. Prévot et J. Peyrin for their help with the measurements.

The exposure time was $2 \times 2$ hours for all plates. The plates are not numerous and of insufficient quality for yielding accurate results. However a radial velocity larger than $100 \mathrm{~km} \mathrm{~s}^{-1}$ has been measured on at least two different plates for the 7 first stars of Table 1 and can be considered as certain.

The results are less certain for the 4 following stars (Nos. 8 to 11) for which the spectra are underexposed and the lines broad. They have to be confirmed by further measurements. Star No. 11, contrary to all the others, seems to have a large negative radial velocity, but it is faint and has broad lines.

Star No. 12 has hydrogen lines in emission and its large positive velocity has been mentioned by M. and A. Duflot.

It is clear that the measured stars may have variable radial velocities and that superimpositions on the plates might yield incorrect results. I found it interesting however to mention their existence.

Table 1 gives approximate coordinates for the stars as measured on a 4 times enlargement of Chart 3 of the Canterbury Sky Atlas (Doughty et al. 1972). Figure 1 shows identification charts. The OM numbers (last column) follow those of the stars studied in previous publications (Carozzi 1971, 1974). The radial velocities are too uncertain to be given in the table.

The dates of the plates are given in Table 2 .

Acknowledgements. I thank Mrs. M. Duflot who gave me the plates, and all the personnel of the Marseilles Observatory.

\section{References}

Carozzi N., 1971, A\&AS 4, 231

Carozzi N., 1974, A\&AS 16, 277

Doughty N.A., Shane C.D., Wood F.B., 1972, Canterbury Sky

Atlas, Australis. Mount John University Observatory

Rodgers A.W., Roberts W.H., Walker I., 1993, ApJ 106, 591 
Table 1. Coordinates and identification of the stars

\begin{tabular}{|c|c|c|c|c|c|c|c|c|}
\hline $\begin{array}{c}\text { No. } \\
\text { (chart) }\end{array}$ & $\begin{array}{c}\alpha \quad(2 \\
\mathrm{h} \mathrm{m} \mathrm{s}\end{array}$ & 00) $\delta$, & $\overline{\mathrm{Sp}}$ & & Plates & & Identification & $\begin{array}{l}\text { No. } \\
\text { OM }\end{array}$ \\
\hline 1 & 223,0 & -7040 & $\bar{A}$ & 5855 & 5869 & 5872 & & 107 \\
\hline 2 & 225,3 & -7022 & A & 5855 & 5869 & 5872 & & 108 \\
\hline 3 & 238,7 & -7019 & $\mathrm{~A}$ & 5855 & 5869 & 5872 & & 109 \\
\hline 4 & 242,0 & -6851 & G-K & & 5869 & 5872 & & 110 \\
\hline 5 & 39,4 & -6737 & $\mathrm{~A}$ & 5874 & 5881 & & $\begin{array}{c}\text { P 83s-8 11,9 A2 } \\
\text { Rodgers et al. (1993) }\end{array}$ & 111 \\
\hline 6 & $3 \quad 9,7$ & -679 & $\mathrm{~K}$ & 5874 & 5881 & & CPD-67 209 & 112 \\
\hline 7 & 332,4 & -6946 & A & 5858 & 5864 & & & 113 \\
\hline 8 & 220,9 & -7138 & G-K & & & 5872 & HD 14979 11,4 K0 & 114 \\
\hline 9 & 224,8 & -7138 & G-K & & & 5872 & & 115 \\
\hline 10 & 228,5 & -716 & $\mathrm{~A}$ & 5855 & 5869 & 5872 & & 116 \\
\hline 11 & 321,5 & -6756 & $\mathrm{~A}$ & 5874 & 5881 & & $\begin{array}{c}\text { P 831-8 13,2 A2 } \\
\text { Rodgers et al. (1993) }\end{array}$ & 117 \\
\hline 12 & 144,3 & -7440 & $\mathrm{H} \mathrm{em}$ & 5868 & & & & 118 \\
\hline
\end{tabular}

Table 2. Dates of the plates

\begin{tabular}{|c|c|c|c|c|c|}
\hline Plate & Date & $\begin{array}{l}\text { TU } \\
\text { h m }\end{array}$ & Plate & Date & $\begin{array}{l}\text { TU } \\
\text { h m }\end{array}$ \\
\hline 5855 & 15 November 1982 & 358 & 5869 & 7 December 1982 & 315 \\
\hline 5858 & 17 November 1982 & 439 & 5872 & 10 December 1982 & 5 \\
\hline 5864 & 20 November 1982 & 429 & 5874 & 12 December 1982 & 319 \\
\hline 5868 & 6 December 1982 & 3 & 5881 & 22 December 1982 & 314 \\
\hline
\end{tabular}



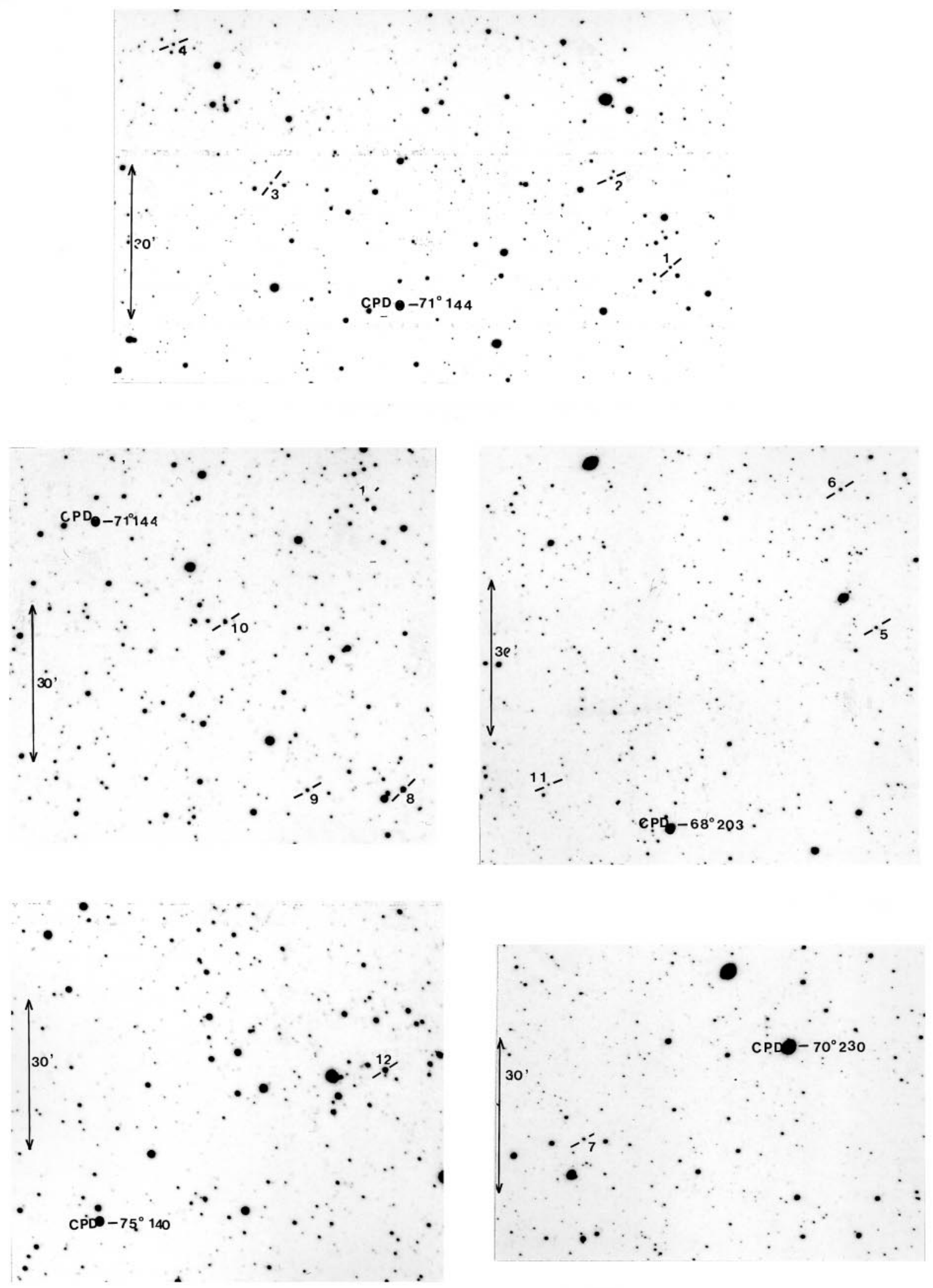

Fig. 1. Star positions on excerpts of Chart 3 of the Canterbury Sky Atlas (Doughty et al. 1972) 